\title{
RECOMMENDATIONS ON SOCIAL SUPPORT TO FAMILIES AFFECTED BY HIV/AIDS
}

\author{
Tetiana Liakh \\ Borys Grinchenko Kyiv University, Ukraine \\ Tetiana Spirina \\ Borys Grinchenko Kyiv University, Ukraine \\ Tetiana Alieksieienko \\ Institute for Education Problems, National Academy of Pedagogical Sciences of Ukraine, \\ Ukraine
}

\begin{abstract}
The purpose of this article is to provide recommendations for social workers and social field practitioners of state and non-governmental organizations working with families affected by HIV/AIDS. The article identifies a series of crisis stages of families affected by HIV/AIDS. Families caring for HIV-positive children go through four crisis stages. The first stage comes after the report about an unconfirmed possibility that a child has HIV. The second stage is when the diagnosis confirms the child's HIV positive status. The third stage coincides with the first signs of opportunistic infections in the child. The fourth stage is associated with the progression of the disease and the development of the fourth clinical stage of HIV infection. At each of these stages, families need medical, psychological, and social support. In line with professional support, an effective method of assistance and a way to overcome a crisis can be self-help groups, in which people learn to voice their difficulties and problems, seek support or provide it to other families.

Using the results of the study gained through focus groups with social work practitioners from various regions of Ukraine, the authors developed recommendations on supporting families affected by HIV/AIDS.
\end{abstract}

Keywords: HIV infection; HIV-positive status; children living with HIV; social services; social workers; families affected by HIV/AIDS.

\section{Introduction}

HIV and AIDS are worldwide problems that have affected every country and the number of HIV-positive people is currently increasing. Ukraine also has an HIV epidemic.

Prevention and response to the HIV/AIDS epidemic have been recognized as one of the national priorities in Ukraine, as the problem of HIV infection has moved beyond a purely medical one. In Ukraine, the rate of social or biological social orphanhood of children due to HIV is increasing.

The current epidemic situation in Ukraine is characterized by a shift in the main route of HIV transmission from parenteral (via blood) to sexual, the rapid 
spread of HIV infection among persons who are not at high risk for HIV infection (that is among general population - sexually active people). The number of HIVpositive people of reproductive, working-age is increasing and, consequently, the rate of HIV-positive women of childbearing age and children born to them, and therefore the growth in the number of families affected by the HIV/AIDS problem. In most cases, social work practice in Ukraine considers such families as "vulnerable" or "families in difficult life situations" that need social support.

In Ukraine, there is a wide network of state and non-governmental HIVservice organizations, the specialized social services have been created at the Centers for Social Services for Family, Children and Youth. to support families affected by the HIV/AIDS problem.

In this regard, the priority tasks are to organize effective social work with families affected by the HIV/AIDS problem, to expand and optimize the range of social services of this group, taking into account the problems that cause the vulnerability of such families.

The purpose of our study is to develop recommendations on support families affected by the HIV/AIDS problem, based on objective information about its effective forms and methods, obtained through focused interviews with experts from HIV service organizations.

\section{Literature review}

The conducted study «Psychological adjustment in caregivers of school-age children infected with HIV: stress, coping, and family factors» (Bachanas et al., 2001) is interesting for understanding the features of psychological adaptation of persons who substitute parents of HIV infected children. The value of the findings in this and subsequent studies (Lachman, Cluver, Boyes, Kuo, \& Casale, 2014) is increasing as experts in HIV service organizations in Ukraine point out that a large proportion of children with HIV are currently being cared for by parents substitute. Often these are grandparents, older relatives. Therefore, social workers and psychologists of HIV service organizations usually address the issue of emotional burnout prevention, coping with stress, increasing parental competence.

Social support and family resources have been found to be an important factor in long-term coping with a chronically or terminally ill child (Kupst \& Schulman, 1988). These factors seem particularly important for children and families living with HIV disease, as most of these families live in inner-city environments and must cope with the stresses of poverty, violence, and drug use (Mellins \& Ehrhardt, 1994). In addition, many families must cope with their illness in isolation due to the stigma of HIV disease and their fear of rejection and 
abandonment by friends and family. Consequently, many families have limited social and emotional support.

«The Family Responses to HIV/AIDS in Mexico» (Castro, Orozco, Aggleton, Eroza, \& Hernandez, 1998) study is useful for understanding the responses of two marginalized communities to the lives of families affected by HIV/AIDS.

The study «Stigma and psychosocial wellbeing among children affected by parental HIV in China» (Domlyn, Jiang, Harrison, Qiao, \& Li, 2019) proved the importance of psychosocial support to children whose parents are HIV-positive as it further affects the mental health of children.

The scientific group (Richter et al., 2009) made a comparative analysis of numerous studies and pointed out the importance of complex support to families affected by HIV/AIDS to ensure the best interests of children living in these families.

The scientific work «A study to assess the needs of people living with HIV/AIDS reporting to an ART Center of Central India» (Taneja, Dixit, Yesikar, \& Sharma, 2013) analyzes the needs and problems of people living with HIV/AIDS that are registered with the HIV-service organization, receiving different types of support.

\section{Methodology}

The focus group method was applied in the study. Its purpose was to obtain qualitative data from participants to describe the methodological framework and justify the methods, forms of support to families affected by HIV/AIDS. The participants were experts with practical experience in the field.

The focus group method is a group interview conducted by a moderator according to a pre-developed scenario with a small group of respondents. The participants are sampled from the study population and represent similar social characteristics. Our focus group was based on the methodology developed by American sociologists (Merton \& Kendall, 1946).

Respondents were invited to participate in the focus group through proposals in a letter addressed to specialists of HIV-service organizations of Kyiv and Cherkasy regions.

To conduct the focus group, we have selected two groups of equal number (12 people each) among social work practitioners from 4 HIV-service organizations in the Kyiv region and $4 \mathrm{HIV}$-service organizations in the Cherkasy region.

For each HIV-service organization, 3 persons have been selected who have a different experience, higher education and common field of activity. 
The first focus group included experienced social work practitioners with more than 10 years of work experience with HIV-positive persons. The second focus group included social work practitioners with less than 10 years of work experience with HIV-positive individuals. This grouping made it impossible for more experienced colleagues to put pressure on less-experienced workers, which allowed the authors to compare the responses of the focus group participants.

\section{Table 1 Information about respondents}

\begin{tabular}{|c|c|c|}
\hline & Focus group 1 & Focus group 2 \\
\hline Total & 12 & 12 \\
\hline Age range & $22-55$ years & $22-55$ years \\
\hline \multirow[t]{3}{*}{ Experience (\%) } & $1-5$ years -0 & $1-5$ years $-7(37,5 \%$ \\
\hline & $5-10$ years $-3(25 \%)$ & $5-10$ years $-5(37,5 \%)$ \\
\hline & More than 10 years $-9(75 \%)$ & More than 10 years -0 \\
\hline \multirow[t]{3}{*}{ Position (\%) } & $\begin{array}{l}\text { Social work practitioners - } 5 \\
(41.7 \%)\end{array}$ & $\begin{array}{l}\text { Social work practitioners - } 8 \\
(66.6 \%)\end{array}$ \\
\hline & Head of department $-3(25 \%)$ & Head of department - 2 (16.7\%) \\
\hline & Project coordinator $-4(33,3 \%)$ & Project coordinator - 2 (16.7\%) \\
\hline $\begin{array}{l}\text { Education, } \\
\text { scientific degree } \\
(\%) \\
\end{array}$ & High education - $12(100 \%)$ & High education - 12 (100\%) \\
\hline $\begin{array}{l}\text { Represented } \\
\text { institution (\%) }\end{array}$ & $\begin{array}{l}\text { State agency - } 2(50 \%) \\
\text { NGO - } 2(50 \%)\end{array}$ & $\begin{array}{l}\text { State agency - } 2(50 \%) \\
\text { NGO - } 2(50 \%)\end{array}$ \\
\hline
\end{tabular}

$n=24$

According to the methodology of grounded theory, encoding occurred simultaneously with data collection. Initial encoding was open and close to the text, this means that the codes were designed to reflect the actions, intentions and meanings of the respondents, often using their own words. Further interview encoding was the current use of comparative analysis, which made it possible to identify such codes into categories. The answers were carefully analyzed and some minor changes made. The authors used MaxQDA for data processing.

After the initial isolation of the categories, it modified the process of attracting participants. To provide the most diverse selection, participants were selected according to their ability to explain the specific issues, which had been identified in the previous study. This approach is called "theoretical sampling" (Glaser, B.G. \& Strauss, A.L., 2012) and it allows for formulating specific questions for interviews. Based on the focus-group results, the methodological characteristics, forms and methods of support to families affected by HIV/AIDS were identified, formulated general recommendations on support to families affected by HIV/AIDS, according to the data of the focus groups. 


\section{Research results}

The analysis of the results of two focus groups with participants who have different work experience with HIV-service organizations providing services to families affected by the HIV/AIDS problem showed that such grouping into more or less experienced participants was not effective. We received relatively close answers from experienced and less experienced participants in the focus group. They highlighted the main methodological characteristics of support to families affected by HIV/AIDS. These methodological characteristics are given below.

Participants indicated that they support the following types of families affected by HIV/AIDS:

- families in which parents (one parent) and children (child) have a confirmed diagnosis of HIV - 11 (45.8\%);

- families in which HIV-infected children are raised by caregivers (in foster care / family-type orphanage ) - 4 (16.7\%)

- $\quad$ families in which parents (one parent) have (has) a confirmed diagnosis of HIV and children (child) are (is) HIV-negative - 9 (37.5\%).

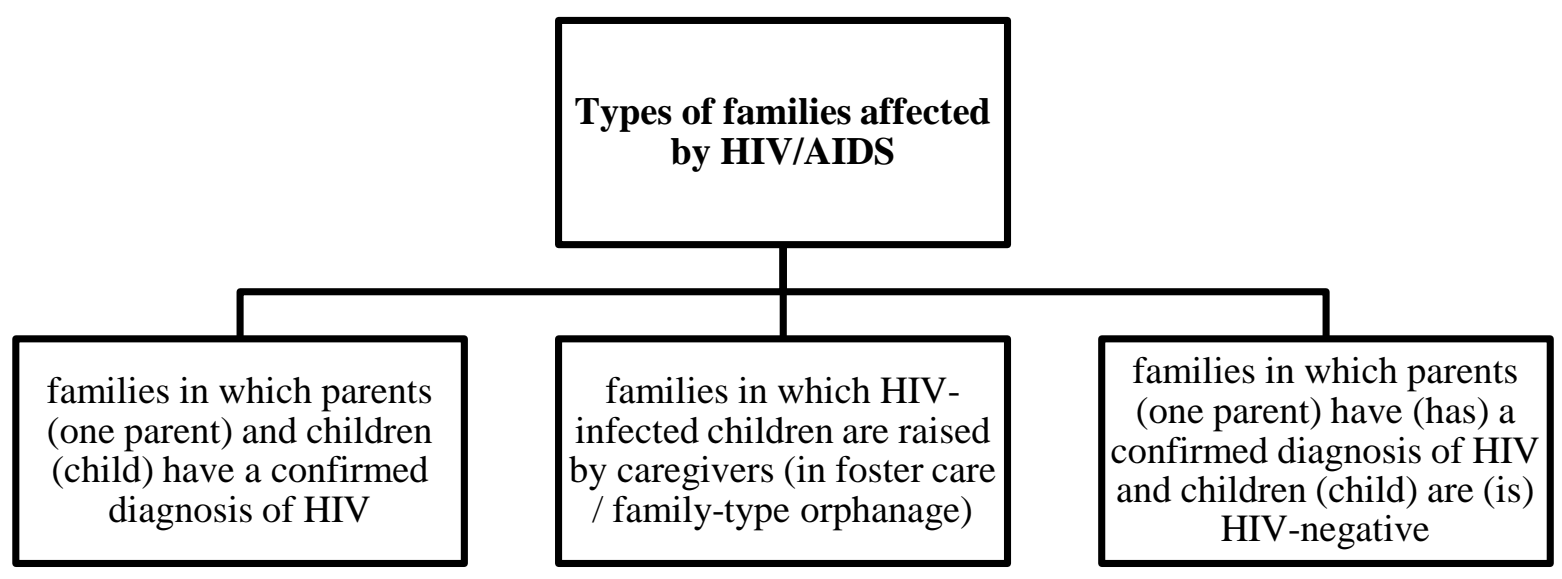

Figure 1 Types of families affected by HIV/AIDS

They also identified the stages that families affected by the HIV/AIDS go through, namely: reporting the possibility of HIV infection of a child; confirmation of the HIV diagnosis of a child; the first symptoms of opportunistic infections in the child; the progression of the disease and the development of the fourth clinical stage of HIV infection.

Participants indicated that at each of these stages families need medical, psychological and social support. In line with professional support, an effective method of assistance and a way to overcome a crisis can be self-help groups, in 
which people learn to voice their difficulties and problems, seek support or provide it to other families.

A self-help group is a group of people who are united by a common life problem or situation. The group members share their feelings and experiences, it provides everyone with a unique sense of empathy and mutual support and also allows bringing together existing information and practical ways of coping. Parents discuss the advantages and disadvantages of disclosing the HIV status of a child, developmental crises of children; how to have fun communicating with your child, how to support a child in the situation of the loss of a loved one. These groups are run by the participants themselves and exist for their benefit. Sometimes experts - doctors, lawyers, psychologists, and social workers - are involved in the work of the group.

Self-help groups change the attitude towards the future of a child and his or her social integration, improve communication between children and parents, and most importantly, change the role from "father/mother taking care of HIV positive child" to simple role "mother/dad, woman/ man, wife/husband".

Participants cited their clients' feedback. For example, Irina: "The biggest change that happened as a result of being part of the group is that she doesn't cry now. She had a lot to do and struggle to overcome her child's problems at school. Now the girl has a lot of friends, she wants to get higher education and doesn't skip lessons." Irina (Kyiv) is a woman who has two adoptive and two biological daughters. Two children are HIV-positive. She has always been a source of inspiration for other moms in issues of bringing up and caring for children. During recent meetings, she has already begun to talk about her women's needs.

The protection of the rights of HIV-positive children requires strong state support, particularly in terms of providing proper conditions for their development. When children reach the appropriate age they go to the kindergartens and other educational institutions; therefore, they move from their family environment into a society. This requires the preparation of a positiveminded public opinion, which would avoid many negative effects or actions on the part of the local community. Families in which adults or children have HIV are affected by multiple socioeconomic and medical problems, the most severe are associated with poor access to social and health services; risks of stigma and discrimination; difficulties in educational opportunities. These factors cause a significant drop in the living standard of such families and increase their vulnerability. Moreover, there is a need to change the focus of defining HIV: society must recognize that the disease is not only medical but also a social issue. This approach helps to provide children and adults with more educational information about HIV prevention and treatment and simplify the process of children's inclusion in school and extra-curricular institutions. 
The analysis of the results of two focus groups shows that in Ukraine the following educational activities are carried out working with families raising HIV-positive children: organizing and conducting thematic classes, seminars for parents, methodological gatherings of center staff; involvement of city infectious disease specialists to conduct classes on the medical and social aspects of HIV/AIDS. Non-governmental organizations have introduced their own training courses for the education of social workers. It is important to note that such educational training courses are not long-lasting and give only certain aspects of socio-pedagogical work, they don't cover the whole system of assistance and care for HIV-positive children and their families.

Professionals working with families raising HIV-infected children should be guided by the following principles: respect for and protection of constitutional human rights; targeting and individual approach; a voluntary choice to receive or to refuse the provided social services; humanity; legality; privacy.

Today in Ukraine, there is a need to prepare social workers to work with families caring for HIV-positive children. For this reason, social workers should have a formed set of skills: to provide clients and their families with qualified targeted social services at the centers of social services for families, children and youth or other state institutions and agencies; to inform clients and family members about the activities of organizations and self-help groups of people living with HIV/AIDS; to provide social support to HIV-infected children and their families under individual plans and contracts, to provide social patronage for AIDS patients at the terminal stage at home; to provide involvement of children, people living with HIV/AIDS, and their families into specialized social services for families, children and youth, their participation in thematic classes, sociocultural activities; to assist in the placement of children with HIV/AIDS in preschool and school institutions; to promote the formation of clients' healthy lifestyle skills; to carry organize and conduct social programs and special health programs for families with children affected by HIV/AIDS; to disseminate thematic information materials and specialized literature about life with HIV among clients.

Considering the patient's right to privacy about diagnosis, to the confidentiality of their medical information and treatment, social workers often identify such individuals as HIV-positive in case of their self-disclosure. Information about the HIV status of a child or HIV status of family members can be received from a doctor of AIDS center or from the body of guardianship with a note "For Official Use Only" for the sole benefit of a minor child in a lifethreatening situation.

In addition, families affected by the HIV/AIDS can be identified and draw the attention of social services by other signs of vulnerability: poverty, family conflicts, violence, neglect of child's needs, and others. Close cooperation 
between social services, health care and NGO AIDS-service organizations make it possible to identify and provide appropriate services for families affected by HIV/AIDS and families in difficult life situation because of HIV status. The basic findings and conclusions of the study were discussed and received positive feedback at the meetings of Social Pedagogics and Social Work Department of the Institute of Human Sciences, Borys Grinchenko Kyiv University.

\section{Conclusions and recommendations}

To summarize the focus group results, the "theoretical sampling" method (analysis, generalization, and comparison of information received) was used to formulate basic recommendations on providing support to families affected by the HIV/AIDS:

- Social workers working with families affected by HIV/AIDS have to know the psychological aspects of a person's perception of his or her HIV status in order to respond effectively to the needs of the family. A person with any serious disease, including chronic illness, perceives the disease as one of the most traumatic events in their lives. As a result, such experience affects the physical and mental state of the patient. Foremost, there are negative emotions: fear, anxiety, pain, suffering, anger, guilt, which are manifested differently at different stages of the disease and its treatment. An adult is not always able to cope with these feelings; it is even more difficult to handle for children.

- Social workers should consider whether the child has been informed of the parents' HIV status or his or her HIV status in order to avoid situations of unplanned, not agreed with family members and traumatic disclosure of HIV status. This is extremely important in the context of psycho-emotional consequences for the child who has not been prepared to receive such information. Barriers to disclosure include fears of the child disclosing his or her status to others and can become subject to stigma, which can have negative effects on his or her emotional and physical health.

- The main characteristic of case management working with families when children are taken from a special medical registration, but parents have disabilities related to HIV infection is developing ongoing cooperation with close relatives. This is done to improve the quality of care, the relationship between family members, and to involve them in the process of caring for a child. The social worker should be aware that after the death of the biological parents, the child must retain family roots, that is, to stay with the relatives, to be under their guardianship 
and care. If a child has no close relatives, after the death of the parents, the social worker together with the specialists involved should contribute to the placement of a child in family forms of parenting for orphans and children deprived of parental care.

- A psychologist should be involved in work with the family. His efforts should be aimed at disclosing the HIV status to the person, preparing the child to a new place of residence, if necessary, and others.

- $\quad$ The features of casework with families affected by HIV/AIDS depend on the number of children in the family. If one child in the family, according to age, knows about the status of the sibling, then tension and rivalry may be observed at the same time as anxiety and worrying about sister's or brother's health. In particular, if more attention is paid to an HIV infected child, a special attitude and need for increased care are emphasized, it can cause irritation of uninfected children and lead to alienation from parents and brother or sister.

- $\quad$ It is not appropriate to restrict the HIV infected child in his or her need for peer communication, education and development. The social worker should explain to parents that their child is just the same as other children; that he or she needs to communicate, to expand the worldview. After confirmation of the diagnosis parents may feel alienation and desire to hide from others, to isolate their child from the outside world. In such cases, parents try to restrict the communication of the a with peers, but such communication is one of the child's basic needs.

- It is important to provide psychological support to a child during hospitalization. Children with HIV may require hospitalization because of their health status. Hospitalization is a major stress for a child. Emotional suffering often increases physical pain and malaise. In order to make it easier for a child to stay in the hospital, it is necessary to explain the purpose of the stay in the hospital, what medical procedures will be performed, how it can affect his or her condition. It is advisable to establish an atmosphere of trust between a child and the medical staff. Do not frighten a child with medical professionals and manipulations. Children can bring their favorite toy with them to the hospital. It helps them feel closer to home and supports at difficult times, reduces the feeling of loneliness. It is much easier to undergo the most unpleasant procedure if a child knows that something interesting and exciting will happen afterward. Every opportunity should be taken to reduce pain during medical procedures. A child needs to know that hospital stay is a temporary measure. 
- It is extremely important when working with a family raising HIVpositive children or children under the age of 18 months born from HIV-positive mothers who are on special medical records to ensure the interdisciplinary interaction of specialists to constantly monitor the timely visits of parents and children to the health care facility they are registered with, to ensure receiving and using antiretroviral therapy; to promote formation of parents' acceptance of child's treatment;

- A social worker when starting a conversation with parents about disclosing HIV-positive status to their child should hold strong arguments for HIV disclosure that would help parents make the decision to speak with their child. There are many aspects to consider when preparing for such conversation, including the child's age, the route of infection, and other important issues. In any case, this conversation should only take place when the child is ready for it.

- It is advisable for a social worker to hold various examples that he or she can use as arguments in conversations with parents.

- A social worker working with the family should maintain regular contact with family members and, if necessary, to hold informational sessions for parents regularly to support the child's adherence to treatment, or to provide psychological support to parents tired of HIV infection.

- $\quad$ Social services should not be provided to parents or family members who are intoxicated; but in this case, the specialist must assess the health and life risk of a child living in this family and to take the appropriate decision in the best interests of a child.

\section{Acknowledgment}

The study was conducted in the framework of the scientific themes of the Institute of Human Sciences of Borys Grinchenko Kyiv University the Institute of human Kyiv University named after Boris Grinchenko "Personality in conditions of social transformations of modern Ukraine "Person under social transformations in modern Ukraine", registration number: 0116U002960, deadline - 5.2016-5.2021.

\section{References}

Bachanas, P.J., Kullgren, K.A., Schwartz, K.S., McDaniel, J.S., Smith, J., \& Nesheim, S. (2001). Psychological adjustment in caregivers of school-age children infected with HIV: Stress, coping, and family factors. Journal of Pediatric Psychology, 26(6), 331-342. DOI: https://doi.org/10.1093/jpepsy/26.6.331 
Castro, R., Orozco, E., Aggleton, P., Eroza, E., \& Hernandez, J.J. (1998, Nov). Family responses to HIV/AIDS in Mexico. Social Science \& Medicine, 47(10), 1473-1484. DOI: https://doi.org/10.1016/s0277-9536(98)00193-2

Domlyn, A.M., Jiang, Y.P., Harrison, S., Qiao, S., \& Li, X.M. (2019) Stigma and psychosocial wellbeing among children affected by parental HIV in China [Article; Early Access]. Aids Care-Psychological and Socio-Medical Aspects of AIDS/HIV, 8. DOI: https://doi.org/ 10.1080/09540121.2019.1687834

Glaser, B.G., \& Strauss, A.L. (2012). The Discovery of Grounded Theory: Strategies for Qualitative Research. New Brunswick \& London. Aldine Transaction.

Kupst, M., \& Schulman, J. (1988). Long-term coping with pediatric leukemia: A six-year follow-up study. Journal of Pediatric Psychology, 13, 7-22.

Lachman, J.M., Cluver, L.D., Boyes, M.E., Kuo, C., \& Casale, M. (2014). Positive parenting for positive parents: HIV/AIDS, poverty, caregiver depression, child behavior, and parenting in South Africa. Aids Care-Psychological and Socio-Medical Aspects of Aids/Hiv, 26(3), 304-313. DOI: https://doi.org/10.1080/09540121.2013.825368

Mellins, C.A., \& Ehrhardt, A.A. (1994). Families affected by pediatric acquired immunodeficiency syndrome: sources of stress and coping. Journal of Developmental and Behavioral Pediatrics, S54 - S60. DOI: https://doi.org/10.1097/00004703199406001-00010

Merton, R.K., \& Kendall, P.L. (1946). The Focused Interview. The American Journal of Sociology, 51(6), 541-557.

Richter, L.M., Sherr, L., Adato, M., Belsey, M., Chandan, U., Desmond, C., ... Wakhweya, A. (2009). Strengthening families to support children affected by HIV and AIDS. Aids CarePsychological and Socio-Medical Aspects of AIDS/HIV, 21, 3-12. DOI: https://doi.org/ 10.1080/09540120902923121

Taneja, G., Dixit, S., Yesikar, V., \& Sharma, S.S. (2013). A study to assess the needs of people living with HIV/AIDS reporting to an ART Center of Central India. Aids CarePsychological and Socio-Medical Aspects of Aids/Hiv, 25(1), 66-70. DOI: https://doi.org/ 10.1080/09540121.2012.686595 